\title{
Time, the body and the reversibility of ageing: commodifying the decade
}

\author{
JUSTINE COUPLAND*
}

\begin{abstract}
Contemporary popular culture proposes new ideological associations between time, ageing, the body and personal identity projects. In a range of magazine texts, television shows and associated websites, several commercialised discourses equate ageing, and women's ageing in particular, with the 'look' of ageing. They project a version of personal ageing that is reversible and repairable, on the presumption that looking younger is universally a desirable goal and one that can be reached through regimes of control operating on skin, body shape and weight, hair and clothing. Different moral stances are established in these discourses. One set offers magazine readers putative control over acknowledged risks and threats deemed inherent to ageing. Such texts invoke personal responsibility for maintaining and indeed for re-claiming a youthful appearance in middle and old age. Another set shames and vilifies people who 'look older than they should'. In those cases, visible ageing needs to be urgently dealt with, on the gerontophobic assumption that the look of ageing renders the individual progressively less socially desirable or even less acceptable. Different frames of mediation, such as the keying of personal censure and humiliation as play, complicate the moral critique of these discourses, even though their ageist orientations are often stark. The decade is constructed as an important unit of bodily ageing, when the target is to look or in some ways to be 'ten years younger'.
\end{abstract}

KEY WORDS - body, appearance, commodification, control, decade, ageism.

\section{'Looking younger'}

Our bodies are an obvious concern in how we manage impressions of our selves in age terms. Ageing is visible, within limits, in the sense that we associate individual ageing with specific physiognomic and physiological traits - changes in body shape, skin and muscle tone and posture - so that these traits take on age-diagnostic value. Discussing facial ageing, Taister, Holliday and Borrman (2000) distinguished between 'intrinsic' genetically

* Centre for Language and Communication Research, Cardiff University, Cardiff, UK. 
programmed ageing and 'extrinsic' ageing, which is linked to environmental factors (particularly sun-damage) and lifestyles (e.g. alcohol and other drug use leading to visible skin damage, such as breaking of veins). They argued that ' $[\mathrm{b}]$ ecause these processes occur independently and simultaneously, the changes caused by extrinsic photoaging enhance and emphasize those produced by innate chronologic degeneration' (2000:2). As this quote shows, the biological account of ageing is explicitly deficitoriented, decremental and deterministic ( $c f$. Coupland, Coupland and Giles I99I), and it is not surprising that personal and social accounts often pattern the same way. People widely share a sensitivity about 'how old they look'.

All the same, there is often a negotiated relativity between age-in-years and age-in-appearance. People do not necessarily 'look their age'. Taister, Holliday and Borrman (2000) conceded that 'a person's biological age may differ - sometimes significantly - from his or her actual age in years' (2000: 2). However, even if this sort of slippage reduces the level of determinism in how appearance is able to predict age (and vice versa), it brings the age-appearance relativity even more sharply into focus. The discourses examined in this paper all find their meaning in the negotiation of appearance relative to age, a rather obsessive concern in popular culture lifestyle magazines, websites and television shows. Not only do these discourses sensitise us repeatedly to 'how we look for our age', they problematise the 'look' of ageing and offer 'solutions' of different sorts to the problems they identify. These are the cultural discourses which entextualise Clarke and Griffin's (2008: 653) claim that 'social invisibility arises from the acquisition of visible signs of ageing and compels women to make their chronological ages imperceptible by the use of beauty work'. As we shall see, they also erase other dimensions of personal and social ageing-ageing that matters to people beyond the simple numbers of chronological age or the tyranny of stereotyped ageappearance.

In popular culture texts, there is repeated emphasis on age-related physiognomy and on the personal problem (as it is represented) of ageing faces, especially women's faces. Consider the two following short extracts. The first is from a feature on 'Looking Younger' in the March 2004 issue of Woman and Home magazine.

\section{Extract $I^{1}$}

Conceal dark eye circles ... get new nude lips ... wave bags goodbye ... plus a skin-booster for smokers. Small changes that add up to a younger-looking you. 
The second extract is from the left page of a double-page advertisement spread titled 'Triumph Over Time!' in the May 2005 issue of Good Housekeeping magazine. The page also depicts a young, glamorous female model. The right page depicts L'Oreal's 'Age Perfect' product range.

\section{Extract 2}

Decrinkle and illuminate your skin in just one step

New for mature skin AGE PERFECT

Double action breakthrough...

'Beauty is not a question of age'

Dayle Haddon, Actress and Grandmother

FROM AGE 5O, MATURE SKIN PROGRAMME

Alongside Extract I, various beauty products are depicted and their use and benefits described. The headline, 'Looking Younger', carries the presupposition that readers of Woman and Home magazine will not only understand the cultural significance of age-appearance relativities, but also appreciate that 'looking younger' and a 'younger-looking you' are conventionally desired outcomes. Imperative expressions such as, 'Conceal dark eye circles', are then to be read as institutionally-prescribed solutions, in the form of disguising or concealing some specific, named, age-salient facial markers (e.g. 'dark eye circles' and 'bags'). These are solutions to a wider, taken-for-granted problem - of ineluctable, visible physiognomic ageing, consistent with the biological model. As a rhetorical design, 'problem with solution' is a recurrent format used in most lifestyle magazines. They embed solutions in specifically marketed patterns of consumption: the solutions have to be bought.

The case of so-called 'anti-ageing' skin-care products being promoted as consumerised solutions to 'the problem of ageing' is one I have considered previously in relation to both female and male target audiences (Coupland 2003, 2007). The first of these studies examined print advertisements for women's skin-care and tanning products (similar to Extract 2), which were found to pathologise ageing in women as young as their twenties. In the 2007 study, I analysed the markedly gendered strategies that, for women, increasingly naturalise surgical intervention as a putative solution to the problem of age-appearance. Male spending on anti-ageing products and processes, and advertising targeted at men, are relatively new. For the male market, products tend to be promoted with ironic statements, addressing 'uncommitted' male stances, or to use highly masculine images and text, and discourses which draw attention to the salience of the female appraising gaze. 
If looking younger is implicitly presented as aspirational in Extract I, in Extract 2 it is referred to more dramatically. The headline 'Triumph Over Time!' posits a battle between the reader and time itself (see Vincent 2007: $95^{2}$ on military metaphors in the promotion of cosmetic anti-ageing products): such discursive framing of time in lifestyle texts is the focus of the present paper. In Extract 2, time is the agent that implicitly 'crinkles' and 'dulls' the skin, a problem for which the L'Oreal product will provide the solution by cosmetic action to 'decrinkle' and 'illuminate' (explicitly mentioned verbs). Stringing together various text elements from the second extract, we can easily reconstruct the proposition that 'skin' may inevitably and inherently be 'mature' 'FROM AGE 50', but that it can easily be rendered 'AGE PERFECT' 'in just one step'. One may infer this name of the product range is a state of ageing by which a grandmotherly actress (referred to in the text) and the visual image of a youthfullooking model (pictured in the text) can be easily reconciled, precisely because, in the terms of the text's quotation, 'Beauty is not a question of age'. This aphorism refers to the biological model's concession that we do not always (have to) look our age, although of course the implication is that beauty in ageing is not attainable without the 'double action breakthrough' of the advertised product range.

We can draw on some important perspectives from social theory of the body and ageing to explore these discourses; three in particular. The first is the body as an identity project. Shilling noted that:

In the affluent West, there is a tendency for the body to be seen as an entity which is in the process of becoming: a project which should be worked at and accomplished as part of an individual's self-identity ... in this context, bodies become malleable entities which can be shaped and honed by the vigilance and hard work of their owners (Shilling I993: 5, my emphasis).

Advertisements and magazine features, also skin-care products and their promotion, as typified in the two extracts above, are important mechanisms through which the imperative of body maintenance in ageing is inculcated. Secondly and relatedly, Featherstone pointed out that it is the individual consumer, certainly as $\mathrm{s} / \mathrm{he}$ is addressed in lifestyle media texts, that is assumed to bear moral responsibility for bodily upkeep:

Advertising, feature articles and advice columns in magazines and newspapers ask individuals to assume responsibility for the way they look. This becomes important not just in the first flush of adolescence and early adulthood, for notions of 'natural' bodily deterioration and the bodily betrayals that accompany ageing become interpreted as signs of moral laxitude. The wrinkles, sagging flesh, tendency towards middle-aged spread, hair loss etc. which accompany ageing should be combated by energetic body maintenance of the part of the 
individual - with help from the cosmetic, beauty, fitness and leisure industries (Featherstone I99I: I78, my emphasis).

The moral obligation to maintain one's body and deny ageing is muted in Extracts I and 2, where readers seem to be positioned as collaborators with feature writers and advertisers. The outcome of 'a younger-looking you' in Extract I is projected as being what most readers would naturally desire: the discourse strategies through which reader stances of this sort are quite routinely constructed for readers in lifestyle magazine texts have been analysed in Coupland and Coupland (2009). There are other media texts (see below) in which moral bludgeoning and opinionated evaluation are more evident.

The third and key theoretical perspective is summarised in Featherstone and Hepworth's (I990) concept of the 'mask of ageing', which identifies the tension between the external appearance, or the look of ageing, and the individual's sense of a different, often younger, more authentic, internal self (see Hepworth 2004). It therefore points to potential disjunctions between age-as-appearance (whether assessed by self or another), and different, subjective and socially-salient aspects of age-identity. Mask theory therefore goes well beyond the dualistic framing of age-in-years versus age-in-appearance. It will be important to establish a more nuanced and complex account of how the personal and social 'dimensions' of ageing are appealed to or silenced in texts of different sorts, and to develop a critical perspective on how age-body discourse in popular culture involves an ideological shrinking or curtailment of the semantic field of social ageing.

In the two initial extracts, we began to see something of the relativistic and sometimes paradoxical discourse through which themes of ageing, time and the body are woven into popular culture texts. We will need to consider a wider range of magazine texts, where the moral framing of authoritative media discourses is more prominent. Is 'triumphing over time' in different formulations a liberating opportunity for readers, who can escape the bodily rigours of biological ageing? Should we say that these discourses 'de-essentialise' age, in the sense that, as Extract 2 claims, 'beauty is not a question of age'? Or is 'the problem of ageing' an ideology that is of these texts' own making? We also need to consider other media genres in which these same themes play out to different effects and are serving different commercial demands. Later in the paper I consider data from a British TV series, Ten Years Younger, and its associated web materials. We will see that its format sometimes constructs far more punitive and ageist values for bodily ageing, and shortens the tele-visual time-frame for people to achieve solutions to the putative problem of 
looking 'too old for their age'. Time is constructed and reconstructed in such texts, where the core claim (as in Extracts I and 2 above, but elaborated in different ways) is that the temporality of bodily ageing can be and needs to be halted and reversed. So it should be useful, before turning to the main empirical section of the paper, to review how time in general, and age-time in particular, have been theorised in critical research.

\section{Representations of time and cultural meaning}

Time gives us perhaps the clearest instance of how people agentively impose meaning on social experience through language. Our ways of conceptualising time require us to accept and use particular linguistic categories and relationships that, taken together, make up a conventional mythology of time. Time expressions are often metaphorical, in the way that 'triumphing over time' very clearly is in Extract 2. Hawkes (I972: 60) and many others have observed that languages use metaphorical structures that covertly shape how we understand social phenomena. 'To triumph over time' is a relatively recognisable if less deeply embedded instance, and one that falls within the remit of Lakoff and Turner's (I989) work on the metaphorical conception of time in relation to human life and death. At one point, they considered the metaphor of time as a thief or a changer:

The 'TIME IS A THIEF' metaphor concerns change of a certain kind, the barely noticeable passing of time, and with it, the loss of youth. Many kinds of things change with time: values, landscapes, objects, personal appearance, and so on. ... Because changes occur as time passes, it is possible to personify time itself as being the agent of change, that is, to see time generally as a changer. (1989:40)

So time can be personified as a human actor and as being agentive in the changes that individuals experience over time. Lakoff and Turner built their analysis as follows:

- Life, portions of life and properties such as beauty and youth cease to exist in the passage of time.

- Time inevitably passes. Therefore life, portions of life, and properties such as beauty and youth inevitably cease to exist.

- The passage of time is seen as playing a causal role in these events.

- Time can thus be seen as a metaphorical agent, and the event as an action by that agent.

- Because life and portions of life are possessions, their disappearances are losses and the agent of a loss can be a thief (1989: 37 ). 
This schema makes salient the idea of time and 'portions of life' as commodities, involving the measurement of time passing (years, but also decades - see below), against which we might assess personal change (interpreted as loss of youth and beauty). It is ironic that in Lakoff and Turner's analysis, they endorse one conventional metaphor in explaining another. They accept that time 'passes', and even that this passage is 'inevitable', when ageing as temporal movement 'through time' is fundamentally a metaphorical reading of change and ageing, but the commodification that they point to lies at the heart of the cultural semantics of time. Time is seen as a commodity ('not having enough time'), measured in seconds, minutes, hours, years and decades. While there is a basis in nature for some of these units, time can certainly be said to be over-commodified, particularly when we measure lives in these terms.

Shallis (I983: I5) distinguished this analytic (linear or 'temporal ruler') time, from organic (or cyclic) time, based on repeated natural patterns and sequences, with spring, for example, succeeded by summer, autumn and winter 'always coming full cycle'. Adam pointed out (I995: 25) that 'the invariant, precise measurement [of time] is a human invention' and that it is 'this created time which has become dominant to the extent that it is referred to as time per se'. Thus, measurable and linear concepts of time have not only been naturalised, they have also infiltrated ideologies of human ageing and change. This is a clear example of what Hall (I973: 27) referred to as 'the building blocks of culture ... the isolates of culture, akin to the notes in a musical score'. Hall first distinguished between sacred time (he gives the 'time-less' spiritual experiences in Native American rituals as one example) and 'ordinary clock' or formal time, which is said to be organised by 'sets, isolates and patterns'. A day is a formal 'set', 'deeply rooted in the past' with two primary isolates, day and night (I973: I42). The many perceptual isolates of time include the customarily recognised periods: five minutes, ten minutes, quarter-hours, half-hours and the hour. These and other commodified categories have become our primary indices of time and their inherent arbitrariness is therefore relatively invisible.

Ornstein $(1975: 22)$ pointed out that the complexity of our units of time might be consistent with social ordering in a complex, technological society, but more recent theorising disputes the social utility of objectivised time. Giddens (I98I: I3I) argued that, 'time as pure duration, as disconnected from the materiality of experience, comes to be perceived, in direct opposition to the actual state of things, as real "objective" time because like money it is expressed in a universal and public mode'. The principle underlying measurement schemes in general is universalist - an attempt to ensure that measures of all sort are standardised and universally 
applicable. While this might be an important principle in some material and commercial aspects of social life, in many situations universalist measures fail to reflect our subjective engagement with our selves and other people. This is the case with age-time, by which we inherit assumptions about our 'movement through time' that restrict our options and often work against our interpretations of personal and social ageing. We are left with a sense of what Adam (1995) described as the 'irreversible unidirectionality ... of time', and the view that 'it is not within our gift to reverse processes':

The arrow of time reigns supreme. Humans may slow down the processes of decay and ageing, fix the transient world in concepts and theories, art and artefacts, but they cannot undo their actions. Reversibility has eluded them: ageing and entropy are facts of life and material existence. People get older not younger, cars rust; they do not get newer and shinier (I995: I8).

\section{The decade and dimensions of ageing}

Hall suggested (in I973) that the ten-year decade - the conceptually ordering of years into decadal units - is a relative new cultural isolate of time, but societies have used the decade to formalise important aspects of supposed ineluctable human ageing as a 'fact of life' for many centuries, most memorably with the expression 'the seven ages of man' in Shakespeare's verse. ${ }^{2}$ The decade has achieved mythic status, in Barthes' (1973 [1957]) sense of the myth as an organising, facilitating, seemingly incontrovertible cultural truth. As Tolson put it:

In passing from history to nature, myth acts economically: it abolishes the complexity of human acts, it gives them the simplicity of essences ... it organises a world which is without contradiction because it is without depth ... it establishes a blissful clarity: things appear to mean something by themselves (1996: 5, my emphasis).

Decades have become a 'natural' means of referring to cultural time, by which we routinely associate particular values, styles and tastes with the ig6os, the rggos or whenever. But in the domain of personal time, decades, as in the Shakespeare's ages of man, conventionalise patterns of bodily appearance, capability, social capital, preferences and practices that broadly speaking fill out the decremental biological model. The succession of decades has 'the simplicity of essences', and above all it is a myth premised on non-reversibility.

Decade ageing mythology therefore sets itself against the view that, in post-modern life, the fundamental meanings of ageing are unclear and 
shifting (Coupland 2004) and that, as Adam (1990: 99) put it, 'the meaning of .... ageing .... is socially relative'. Adam cited Weigert (I98I : 216), who claimed that the human lifecourse 'is based on the biological processes of bodily ageing, to be sure, but each of us also pass through intricate networks of overlapping socio-temporal processes which constitute the total experience of ageing in everyday life'. It has become common in social gerontology to recognise that, as Weigert argued, there are multiple temporal networks or dimensions to which social analysis should refer, although different taxonomies exist. I mentioned earlier that biological models distinguish inherited from environmental dimensions of bodily ageing, and that together these constitute an understanding of chronological ageing (age in years). I also noted how chronological models are in conflict with social constructionist models that emphasise the role of language in segmenting and ordering our understanding of human change - what in our earlier work we simply referred to as 'contextual ageing' (Coupland, Coupland and Giles I99I).

On the other hand, Laslett (1989: 24) identified five dimensions of age, labelled chronological, biological, social, personal and subjective. In this list, 'personal age' is 'that moment in the life course which a man, woman or child himself or herself judges to have been reached' (I989: I44), and therefore a normative self-assessment of some sort, and 'social age' is 'public' age, as attributed by family, friends and others (I989: 26). These differ from 'subjective' age, which Laslett held is often 'achronic' and a sense of an unchanging self maintained while 'personal', and 'social' ages change (1989: 26). Aapola (2002) reworked the list in more constructionist terms, arguing that even biological ageing has to be discursively created in social contexts, although 'dimensions of age can be seen as based on more or less established conceptual repertoires, which are often linked to social and cultural institutions' (2002: 297). Aapola thereby proliferated the dimensions of age by nominating chronological, institutional, developmental, physical, biological, medical, experiential, embodied, symbolic, ritual and functional ages. Contextual age is added to these, referring to the estimates and age-attributions made by others in various social situations.

Currently, therefore, although age-in-years is clearly established as the dominant age-metric (Chudacoff I989: 4), with decade-counting as part of that objectivist perspective, an open list of other and more obviously social, subjective and inter-subjective footings for ageing are available. As Baars reminded us, it is 'essential to understand the specific significance and relativity of chronological time and its unfounded seductions in relation to aging', within which 'ever more precise measurements 
[have become] of vital importance to further the range of effective control over nature' $(2007: 3,5)$. Thus, the various dimensional metrics can be brought into play in opposition to each other, generating complex patterns of relative assessments of age. Aapola noted that 'the discourse of embodied age is based on shared cultural understandings of what the body of a person at a particular age should be like' (2002: 307, my emphasis), so there is external pressure on age categorisation over and above the complex set of internal and relational processes just described.

What can result is a series of discursive clashes, with ageing in one dimension perceived as incompatible with ageing in other dimensions, for example when some aspect of socially-attributed age (how old someone looks) is inconsistent with some aspect of biological, personal or subjective age (how old one 'is' or feels one is). This mismatch is exemplified in the words of one of Clarke and Griffin's interviewees (aged 4I years): 'I look in the mirror, and I judge myself, and I wish I looked the way I looked Io years ago.... I think very young but my body seems to have aged faster ... I wish my body would slow down. I want to stay young' (2008: 66o). Thus, the normative context sets up the possibility of censuring and moralising discourses being brought into play, organised around a politics of duty - to look 'good for one's age' and to maintain sufficient symbolic capital in one's ageing body or face.

These are the general discursive possibilities that are exploited in the mass media texts to which I now turn: in these the decade is prominent as a marker of time. The utility of the decade is that, as a perceptual isolate of time, it carries conventional significance in both the chronological and personal dimensions of ageing. Not only is the decade referred to with mathematical and chronological round numbers (age 20s, 30s, 40s and so on), but it has salience in the 'ages of man' rhetoric. We talk of 'people in their thirties', and greetings cards regularly emphasise the significance of decade boundaries, with expressions such as 'flirty thirties, naughty forties, fabulous fifties, sexy sixties' (see Bytheway 2009, in this issue, on decadal birthdays). The chronological/personal duality lies at the heart of decade discourse in anti-ageing product advertising and in a new, hybrid genre of exploitative TV 'makeover' shows. So we have formulas such as: 'Now you can reduce the appearance of wrinkles by Io YEARS without taking the ultimate step' (where a depicted scalpel implies that this 'ultimate step' is cosmetic surgery; see Coupland 2007). There are also invocations to 'Look ten years younger', or to 'Dump a decade' being used as hook-lines for TV programmes, advertisements and magazine features. Human ageing can be construed as a process of accumulating experience and wisdom as we go through life and through the decades, but the idea 
of losing ten years or 'dumping' a decade implies that what we accumulate is simply time itself, along with time's affect on our appearance. So, as we will see, decades can also be construed as undesirable quantitative attributes, like weight, needing to be 'dumped' through technologies of personal appearance. Discursively, the claim is that we can 'lose time' just as we can 'lose weight'.

\section{Bodily control and reclaiming time}

If consumers are to be motivated to buy solutions to visible ageing, then the decade provides a useful device for advertisers, both to impose a decadal phasing on gradual biological change and to quantify the benefits of particular regimes and products in terms of years and decades. Extract 3 is from a six-page advertising feature for Nivea Visage in the magazine Red of July 2005. It asserts the significance of lifespan decade metrics and the distinctive characteristics and 'challenges' said to be inherent for those aged in the twenties, thirties and forties, linking each set to remedial 'strategies'. Three women, apparently aged in the twenties, thirties and forties, are depicted:

\section{Extract 3}

I 20s: Prevention

2 THE CHALLENGES : ... Even though your skin may look radiant and smooth,

3 beneath the surface invisible signs of ageing may already be present... The elastin

4 fibres of the dermis are beginning to degenerate ...

5 THE STRATEGIES : ... cleanse skin and protect from sun ...

6 3os: Maintenance

7 THE CHALLENGES : Expression lines are the first type of permanent

8 wrinkling to appear ... often accompanied by changes in skin texture, colour and

9 firmness...

Io THE STRATEGIES : ... visit a beauty therapist, use anti-ageing cream...

II 40s: Reversal

I2 THE GHALLENGES : ... Collagen production is slowing down, making skin lose

I3 elasticity and firmness ... Age spots, deeper lines and loss of radiance also worsen

I4 THE STRATEGIES : ... a mild peel, fillers and botox, facial exercises, a mild I5 scrub

Extract 3 constructs the mask of ageing, portraying the face as the main semiotic field of decade age-identity, where regimes of treatment can be applied. The text implies that decades are accumulated through ageing, as unwanted skin features. But notice that, in the twenties, ageing is problematised even 'beneath' the look of ageing: there may be 'invisible signs' (line 3), signs detectable only through bio-medical expertise. The advocated strategy is 'prevention', anticipating and seeking to ward off the 
rigours that lie ahead. The thirties are a 'maintenance' decade (line 6), requiring 'anti-ageing cream', a phrase in which ageing is ideologically conflated with age-appearance. Time travel is posited in the forties, which are represented as a 'reversal' decade, inferably past the ideal appearance age, with increasingly technological products and invasive services promoted (lines I4-I5).

Extract 3 rearticulates the presuppositions discussed earlier, about decade-linked progressive facial degeneration, with readers invited to use technology to prevent or mask their visible ageing. The idea of ageing reversal (line II above) is echoed in Extract 4, which is from a one-page advertisement in Good Housekeeping magazine, April 2005. The text is accompanied by an image of a jar of the product Dior Capture and obliquely proposes that readers can look how they did 'Io years ago' by arresting facial changes for the next decade.

\section{Extract 4}

I HOW DID YOU LOOK Io YEARS AGO?

2 SCULPT THE FUTURE OF YOUR FACE

3 GAPTURE

4 SGULPT io

5 Scared to face the future?

6 The face we are born with dictates how we will age. Women with a round

7 face naturally tend towards a double chin, while women with a longer face

8 tend to develop hollow cheeks and thin lips.

9 Capture Sculpt Io $^{\mathrm{TM}}$ is the first anti-ageing range with a solution adapted to the

Io shape of your face, helping you shape your future:

II For a general loss of firmness Lifting Firming Creme or Fluid

I2 For a rounder face with a sagging jaw line: Contouring Gel-Emulsion

I3 For a longer face with hollowing cheeks and thinning lips: Replumping Emulsion

I4 Why wait Io years? Try Capture Sculpt Io ${ }^{\mathrm{TM}}$ at your nearest Dior counter

I5 CAPTURE Triumph over time.

The text describes prospective changes to the reader's facial appearance that can be expected (lines 6-8) and explicitly links ageing, or at least perceptible age-related change, to fear (line 5) (see Woodward ig9i on gerontophobia). But the genetic determinism of appearance outcomes for 'the face we are born with' (line 6) is countered by the science fiction theme of 'triumphing over time'. The last line of Dior's copy here is in fact identical to that used by L'Oreal as the lead line in Extract 2, and another use of the 'time as a thief' metaphor. Extract 5 is the final example of this genre. It is from an article titled 'Dream bodies diet special: dream bodies beauty' in Essentials/Woman's Own magazine, March 2004. It introduces the alliterative 'dump a decade' theme, which also advocates dynamic agentive control over bodies that would otherwise be prey to the decremental changes of biological ageing. 


\section{Extract 5}

I Dump a decade in a week

2 Want a younger-looking face? A svelte body and glossy hair? Follow our

3 guide to knock io years off your looks in just seven days...

4 Saturday (Each day has 3 sections: first 'Diet', then 'Beauty', then 'Exercise'.)

5 Diet: Start a detox

6 The first few days of a detox diet (while you're eliminating toxins and

7 boosting cell renewal) can be tough. You may suffer from mood swings,

8 headaches, tiredness and aching muscles, but these side effects will subside.

9 On the first day of your detox you shouldn't eat anything. Instead, drink plenty

Io of water, adding a squeeze of fresh lemon to cleanse and stimulate the bowels.

I I To quell hunger pangs, drink herbal tea. Three glasses of fresh fruit and

I2 vegetable juice are also allowed.

I3 Beauty: Get glowing

I4 Exfoliation will assist your detox, so every day this week - before bathing or

I5 showering - exfoliate with a body brush, loofah, or body scrub, to rub away

I6 dry, rough patches ... Use an anti-ageing moisturiser on your face...

I7 Exercise: stretching

I8 Do plenty of stretches and slow, deep breathing first thing in the morning and

I9 just before bed. Also take a relaxing stroll in the fresh air to flood your skin

20 with rejuvenating oxygen.

2I Sunday

22 Diet: Add fruit

23 Continue to drink plenty of water and juices, but now introduce small portions

24 of fruit whenever you feel hungry.

25 Monday

26 Diet: Add raw, unsalted vegetables

27 Have a raw vegetable salad for lunch and dinner - do not add salt. Continue to

28 eat fruit for breakfast and for snacks.

29 Tuesday

30 Diet: Add brown rice and cooked vegetables...

The text continues: Wednesday: Add lentils, beans, nuts and seeds ... Thursday: Add grains or live yogurt ... Friday: Add grilled fish, chicken or tofu.... In Extract 5, age-salient symbolic capital is assumed to reside not only in the face but in the physical whole ('your looks', line 3), with anti-ageing work being conceived as a whole-body project of detoxification, exercise and diet. The invitation to conceive a decade as something that can be 'dumped' is both shocking and irresistible. In this formulation, the decade is once again treated as a temporal unit of personal identity, with the self reduced to indices on scales of various sorts (not only age but weight, bodily size and hair texture). 'Dump a decade' implies an agreed typology of personal being, which presupposes the salience not so much of 'being of a certain decade' (as referenced in Extract 3) but rather of 'appearing to be of a certain decade', and specifically the allure of appearing to be a decade younger than one's chronological age, as in Extract 4. But in the formulation in Extract 5, the 
age-in-years basis of personal, subjective and even chronological ageing is supplanted by the criterion of how old we can present ourselves as being. This de-essentialising strategy is liberating, but only if we believe that chronology defines the essential dimension of ageing. The freedom it earns (for those who trust in the discourse) is at the cost of a different form of enslavement, based on the tyranny of personal appearance.

The questions asked in line 2 of Extract 5 are 'rhetorical': a positive answer is taken for granted. Even where age-related change is not explicitly invoked, 'svelte body' and 'glossy hair' are implicitly linked to youthfulness by juxtaposition with lines I and 3. In line I, 'dump' looks as if it might function as a straightforward transitive verb, describing a material action process ('to dispose of', 'to throw down carelessly'), but the usage sets up expectations about what kind of subjects and objects are involved, and implies swift, unceremonious discarding of something undesirable. The haste or lack of care implied in 'dump', as well as the indication of a one-off activity rather than a progressive process, have functional ambiguity: the invocation 'dump a decade in a week' presupposes a 'quick-fix' or 'make-over' culture. ${ }^{3}$ In Extract 5 , however, the three-part regime evidently involves more sustained attention to its detail than the headline would suggest. We may be able to 'dump' household rubbish instantly and unceremoniously, but the regimes and rituals engaged in by participants in order to dump a decade would take time, discipline and self-sacrifice, and might be costly, physically taxing and time-consuming. It is of some moral concern that current media representations of 'down-ageing's reveal individuals undergoing increasingly intrusive and radical regimes, as we will see in the following, final example.

\section{The TV programme Ten Years Younger}

In the United Kingdom, the United States and New Zealand, TV 'makeover' programmes like the UK Channel 4 series Ten Years Younger give control of a subject's bodily appearance to a group of 'experts' who advise on lifestyle (e.g. diet and exercise), change a member of the public's makeup, hair and clothing, and in recent years use increasingly interventionist, including surgical, methods of transforming their participants. ${ }^{5}$ Such programmes are evidently driven by commercial enterprises that approach an aged appearance, particularly that of looking older than one's chronological age, with a problem-solution narrative. The make-over format, repeated in a highly conventionalised pattern, focuses on mostly female subjects (or victims). Extract 6, from an episode of Ten Years Younger, allows 
us to explore how media representations of ageing, change and the decade are formulated for the viewing public. ${ }^{6}$ The extract is of Donna formulating 'the problem':

\section{Extract 6}

I Derby wife and mum Donna Fuller is stuck at home - and stuck in a rut. Since

2 the birth of her toddler two years ago, she's aged horribly. Pregnancy left her

3 with scaly skin which she smothers with a mask of make-up, and lacklustre

4 hair which she chops and dyes herself.

5 The worst problem of all is her gappy front teeth. What's more, she needs

6 coaxing out of her dreary over-sized clothes, and curing of a slouching habit

7 that only Quasimodo would envy. It takes every ounce of expertise the team

8 can summon up to get her looking, and feeling, a vibrant 34 -ten years

9 younger than the age she polled on the streets.

The presupposition of the episode is therefore that Donna is physiologically age-unacceptable. She 'polls' an age of 44 years, and the age targeted for her in the episode is 'ten years younger'. Extract 7 from the same text describes the 'solution'.

\section{Extract 7}

I Donna had:

2 Facial peel, Intense Pulsed Light treatment, botox and dermal fillers by Dr Patrick

3 Bowler.

4 Dental veneers by Surinder Hundle.

5 Hair wefts, cut and colour by Andrew Barton.

6 Fashion styling and deportment exercises by Nicky Hambleton-Jones.

The following transcribed clips from the broadcast TV show illustrates the unfolding narrative (Ten Years Younger, UK Channel 4, I9 January 2005, $8.30 \mathrm{pm})$. In Clip I, the presenter, Nicky, describes Donna's ageingappearance problems. In Clip 2, a voice-over describes the dental and facial treatment Donna will undergo as part of the solution. In Clip 3, Donna is subjected to (pre-transformation) age appraisals, in which strangers guess her chronological age from her appearance ('age-polling'). In Clip 4, Donna's made-over appearance is revealed first to herself and then to some strangers, who repeat the age-appearance appraisals. Finally, in Clip 5, the presenter and the participant appraise the success of the 'ten years younger' transformation and what it apparently means to Donna.

Clip $I$

(Nicky, the presenter, introduces Donna to the experts.)

I gentlemen we have work to do (.) our contributor today is Donna (.)

2 she's 38 years old but the poll says she looks 44 (.) she has one child 
3 but she looks like she has five (each expert gives their 'verdict') ...

4 here's the plan to turn Donna from dowdy to diva ... her skin will

5 have laser treatment and botox (.) she'll be given a sparkling

6 Hollywood smile (.) sassy slinky clothes and a sexy haircut

\section{Clip 2}

(A male voiceover describes the make-over strategy.)

I first Patrick puffs up the pockmarks with filler ... he kills off those

2 crows' feet and irons out her wrinkles with a barrage of botox ...

3 laser treatment is the only way to get rid of redness

4 Donna has a grandmotherly gummy smile (.) cosmetic dentist Surinda

5 promised her perfect teeth ... Donna's hoping for a Hollywood smile

6 but will she still look as old as the hills? ... veneers are the only option

7 especially when your choppers are as chronic as Donna's

\section{Clip 3}

(Donna stands in the street and is subject to the gaze and appraisal of strangers. The male voiceover comments.)

I Derby mum Donna Fuller is only 38 but when roo people

2 were asked to guess her age the figure was bigger

\section{Clip 4}

(Post make-over: The 'reveal'. The participants are Donna (D), the presenter, Nicky (N), the male voice-over $(\mathrm{V})$, some young male bystanders $\left(\mathrm{YM}_{\mathrm{I}}, \mathrm{YM}_{2}, \ldots\right)$, a young female bystander (YF), and a middle-aged female bystander (MF).)

I V: four weeks ago Donna Fuller looked down (.) and out (.) her dry

2 damaged hair (.) poor posture (.) and stained smile made her

3 look haggard and harassed (I.0) not any more

[The 'Reveal']

$4 \mathrm{~N}$ : (standing next to a full-length mirror) come and have a look

5 D: (looks in the mirror; gasping and smiling) oh my God (.) it's not me it

6 can't be (.) it'll take me a week to get over the shock

7 (laughing) the clothes (.) the hair (.) so different to any colour that I've

8 ever had before the make-up er I'd never think of wearing this colour

9 lipstick but obviously now I've had my teeth done I can (.) I can't

Io believe how how different I feel

II N: how young do you feel?

I2 D: (smiling) about 2I!

I3 $\mathrm{N}$ : fantastic!

(We see side-by-side, before-and-after images of Donna, music.)

I4 V: in just under a month Donna's home-cut listless hair

I5 has become textured and sexy (.) her scaly skin is now silky

I6 and smooth (2.0) her posture's perfect and so are her clothes (2.0)

I7 and her fresher face lights up with her new $\overline{(.)}$ Hollywood smile 


\section{Clip 5}

(Donna and Nicky are seen walking down Carnaby Street, ${ }^{7}$ to Roy Orbison's Pretty Woman. Donna is again subject to the gaze and appraisal of strangers, who comment evaluatively.)

I V: Donna thinks she looks younger (.) but do the public agree?

$2 \mathrm{~N}$ : what age do you think Donna is?

3 YMr: (hesitantly) er thirty-two

$4 \mathrm{YM}_{2}$ : thirty at the most

$5 \mathrm{YM}_{3}$ : good wavy hair great backside (Donna and Nicky are heard shrieking

6 with laughter) ((be)) about twenty-nine

7 YM4: she's got nice styled hair big smile good figure (.) about twenty-nine?

8 YM5: very nice looking I think (hesitantly) about thirty-seven

9 YFI: thirty-five she's got lovely teeth which is ((all))

Io MF: she looks about twenty-five? (presenter looks agape) nice smile (.)

II good teeth

(Donna and Nicky clasp each other's hands as if in victory.)

I2 V: well it's looking good but there's always one time (.) they can't turn

I3 back (.) our moment of truth

(Donna and Nicky are seen sitting at a street café with glasses of wine.)

I4 N: now before I reveal (.) your new age tell me what you've learnt

I5 D: before I started I I assumed that everything that was wrong with me

I6 was because I was a mother (.) because you know I blamed it all on

I7 my poor little baby (winces) (.) and I feel really bad about that now

I8 because (.) it wasn't him it was me you know (.) smoking poor diet not

I9 looking after my hair not looking after my skin you know it w-it was

20 really all my fault I think I'm going to actually enjoy being a mother

2I from now on and not feel that it's you know a a hard job

$22 \mathrm{~N}$ : you're thirty-eight years old

23 D: yes

$24 \mathrm{~N}$ : but when I met you your poll age was forty-four

25 D: (nodding) yes

$26 \mathrm{~N}$ : so our challenge was to make you look thirty-four $=$

$27 \mathrm{D}: \quad$ (nodding) $=$ yes (holds up her hands, looks tense)

$28 \mathrm{~N}$ : well Donna (2.0) we have achieved our goal and you are now (.)

29 thirty-four

3o D: oh thank god for that!

3I N: $\overline{\text { are you pleased? }}$

32 D: yes I'm very pleased I'm ecstatic yes um (.) it's just (.) so nice to

33 actually feel younger than what I am

$34 \mathrm{~N}$ : well it is (clinks wine glasses) hello to Donna the diva

35 D: (laughing) yes

$36 \mathrm{~N}$ : and (clinks wine glasses, both laugh) goodbye to Donna the cleaner

(An end of show trailer introduced the male recipient of the following week's make-over, and the programme was ubiquitously framed by an advert for RoC io Years Younger skin cream.)

Donna's chronological age is $3^{8}$ years. In the show's reality, however, based on bystanders guessing her age at 45, 42 and 5o, the average age appraisal figure is 44 . What is the cultural and generic status of this 
data? First and foremost, it is a highly commercialised TV format, designed to promote the participating experts (whose transforming skills are also available, at a cost, to the general viewing public). The Ten Years rounger formula (in that an identical sequence of scenes and activities is repeated weekly) is not only a 'problem-solution' sequence, similar to the magazine texts we considered earlier, but also a romance or a quest story (Harré 1983; Murray 1990). This is unashamedly voyeuristic material that lays bare the bodily 'weaknesses' of the subjects, and in that sense is characteristic of recent radio and TV programming that interfaces between private and public domains (Dovey 2000). The programme, its website and a linked, highly publicised book are glossily produced and weave an elaborate web of consumerist practices, including the sponsoring TV advertisements that frame the programme, with 'RoC Io Years Younger' skin cream prominent in this episode.

Highly crafted and scripted, much of the website material and the voiceover commentary in this programme series is styled to be droll and playful, marked by figurative language, tropes and hyperbole such as, 'she needs ... curing of a slouching habit that only Quasimodo would envy' (Extract 6, lines 6-7); 'Patrick [the dermatologist] ... kills off those crows' feet and irons out her wrinkles with a barrage of botox' (Clip 2, lines I-2); 'when Ioo people were asked to guess her age ... the figure was bigger' (Clip 3, lines I-2); 'her dry damaged hair (.) poor posture (.) and stained smile made her look haggard and harassed (I.o) not any more' (Clip 4, lines $\mathrm{I}-3$ ). Rhythmic and alliterative features here suggest playful key, but this is in uneasy contrast with blatantly ageist attributions, as with 'she's aged horribly' in Extract 6, line 2, and the catalogue of personally demeaning and humiliating evaluations, in public and on camera. Some of the experts' discourse around the make-over process appears designed to be shocking as well as comical, and the on-the-street 'before and after' appraisals by strangers are characteristic of TV programming's current use of 'controlled controversy' (Dovey 2000), as they subject participants to extreme personal face-threats (Brown and Levinson I987 [1978]; Goffman 1959) to accentuate the dramatic qualities of the exchanges.

MacDonald (2003) observed that media texts can be ideologically influential even while framing their messages ironically: 'In discussions of the media, irony is often claimed to pose a challenge to all forms of serious discourse. If everything is 'tongue in cheek', ideology may indeed become obsolete or at least moribund. But playful irony does not necessarily contest established power' (2003: 28-9, my emphasis). MacDonald cited Eagleton (I99I: 40), who similarly argued that 'such irony may act as a seductive 
decoy to distract attention from the underlying ideological purpose'. Along these lines, we can draw out a number of linked ideological presuppositions about time, the body, ageing and change in the presented Ten Years Younger clips. Firstly, looking older is not only problematic ('she's aged horribly'), but looking 'bad' is equated with looking older (Donna's pre-makeover age-appearance 'made her look haggard and harassed'). Secondly, looking younger is presumed to be what Donna and all of us aspire to, but also worth the investment of time and expert effort (cf. Shilling I993 on the 'body project'). Here, the presenter's line is that 'we have work to do', and the collaborative effort at age-appearance transformation is undertaken with missionary zeal: 'It takes every ounce of expertise the team can summon up to get her looking, and feeling, a vibrant 34 '.

Thirdly, there is the assumption that age, time and the decade, like Donna herself and her embodied physical and stylistic attributes, are commodities that are amenable to objective assessment, even by casual observers on the street, and manipulation. The show's concept of Donna having a 'poll age' reduces ageing to a single numeral, albeit one that can be creatively manipulated. And in that manipulation is a fourth assumption, that the passage of time for an individual can be reversed, controlled or 'cheated', and that appearance age becomes actual age in this achievement. Notice how the show discourse sets up its own criterion of inalienability: 'well it's looking good but there's always one time (.) they can't turn back (.) our moment of truth' (Clip 5 , lines I2-I3). The show positions itself as the ultimate arbiter of ageing. Its technologies generate real ages, or the only ages that matter. As Nicky says, 'well Donna (2.0) we have achieved our goal and you are now (.) thirty-four' (Clip 5, lines 28-29), to which Donna replies 'oh thank god for that!' Fifthly, it is assumed that age-appearance is measurable through the gaze of others and can be 'read off' from individuals' bodily display; in this case, in terms of sexual appraisals made by men, such as having a 'great backside'. And sixthly, that losing or 'dumping' a decade is necessarily cause for celebration, as signalled by the discursive apparatus of tension and release in Clip 5 (lines 26-30). Donna says she is 'ecstatic', despite the ontological muddle of the terms of her achievement: 'it's just (.) so nice to actually feel younger than what I $\underline{a m}^{\prime}$.

\section{Discussion}

The texts we have considered all build on contrasting age-related appraisals. The first are contrasts between biological/physiological/ 
physiognomic ageing and other 'contextual' dimensions, which include aspirational ageing, how old we aspire to be. They exploit these contrasts for commercial gain, either through selling skin-care and similar products and treatments or through audience ratings. Secondly, the magazine texts and the Ten Years Younger TV programme texts also build on a 'before and after', pre-intervention/post-intevention temporal contrast, and the urgency and drama of a transformed appearance is what provides momentum. The trope of the media 'reveal' in Ten Years Younger, after the final phase of arranging hair, make-up and clothing in the Donna episode, distils the transformation and evidences its apparent success in the eyes of the audience and, crucially, in Donna's mind. Magazine texts have to leave readers to take these transformative effects on trust.

The uncovering of a mirror (Clip 4, lines 5ff.) amounts to a neat transposition of Featherstone and Hepworth's mask of ageing. Whereas the iconic practice of the mask of ageing is to look in the mirror and see an 'older exterior self', Donna's older subjective self (she 'is' 38 but was judged 44) is separated from her 'younger' body as she momentarily claims not to recognise herself. She says, 'oh my God (.) it's not me it can't be' (Clip 4, lines 5-6). In fact, what Donna 'is' after her make-over, and what women readers of texts in the 'looking younger' genre might feel they will be, remains elusive. Assuming they endorse the ideological assumption that appearance matters most, 'internally' in relation to age-identity, rather than chronological age, are they able to sublimate all other dimensions of ageing - institutional, developmental, physical, biological, medical, experiential, embodied, symbolic, ritual and functional - to this sole criterion? Are they prepared to pass responsibility for the meanings of their own ageing to bystanders' quantitative appraisals of how chronologically old they appear to be in physical and sexualised terms (Aapola 2002: 298)? Does Donna believe she has 'lost' ten years? We cannot know this, on the basis of the discourse alone, although Donna does refer to feeling as well as looking younger (Clip 5, lines $32-33)$.

Nor can we be sure how sincerely Donna, or the viewers for whom she is displayed as a mediated prototype, feels the chastening effects of her own moral failures around physical ageing, as the show projects them to be. The moral coda in the Ten Years Younger sequence, during which Donna is called upon to rehearse what her participation has taught her, conforms with Featherstone's observation (see above) that 'bodily deterioration and the bodily betrayals that accompany ageing become interpreted as signs of moral laxitude'. When Donna admits that her loss of bodily control amounted to 'everything that was 
wrong with me', she voices the guilt that the magazine texts only hint at (as in the suggestion in Extract 5 that 'to knock Io years off your looks' is universally desired). And it is in the promotion of guilt and contrition in response to physical ageing, as much as in the promise of easy, controlled, commercially available technological solutions, that the ideology of anti-ageing and age-reversibility is potentially most damaging. There is no denying the seductive appeal of halting and reversing ageing, and no denying the subjective and inter-subjective importance of bodily change. As Twigg noted, 'the body is central to the experience of ageing, though the extent of its relevance has been contested, particularly by cultural critics who have sought to emphasise the ways in which aged bodies are the product of the cultural discourses that constitute them and endow them with specific meanings' (2007: 285).

For middle-aged and older women, and increasingly for men of these ages, the idea that the body can be sidelined in the experience of ageing is an impossible ideal. The cultural discourses we have examined, however, and their insistence on the ageing body as a problem and as a necessary focus for remedial work, construct very specific 'relevances' for mass media consumers (cf. Clarke and Griffin 2008). Most obviously, they challenge people's autonomy in constructing their own accounts of the relevance of bodily ageing, and they draw audiences and readers into a consumerist ideology of change. 'Looking good for one's age' is uncontroversially to be desired, but only if we feel we have latitude in deciding what 'looking good' might entail, for us, and in negotiating what the precise relativity might be between appearance and age. Good 'for one's age' might, for example, entail good 'at one's age'.

Formulations such as 'dump a decade' and Ten Years Younger discursively open up the possibility of time travel in midlife and later life, and again it is impossible to deny that regaining relative youth and 'turning back the clock' has a ready appeal. That appeal is entrenched in the mythology of age and in the discourse of reminiscence. In a cultural context in which the body is so heavily invested with symbolic capital, it is difficult at any adult age to resist personal engagement in the commercial body project. But to 'lose' lived time, all of us have to hope, need not in fact be to feign youth. A more complex, multi-dimensional social model of ageing, one less fixated on the physical indexing of age-in-years and on physical attractiveness in relation to age, should ensure that there is some gratification in social ageing, and that, at least in some cases, we might prefer some of our lived decades to be savoured rather than dumped. 


\section{NOTES}

I In the paper I draw on a corpus of high-circulation magazines, published in the United Kingdom between January 2004 and April 2005. Magazine titles were chosen for being at least partly concerned with bodily issues and grooming, and informally judged as aimed at a range of readership ages. The women's magazines are Cosmopolitan, Essentials, Good Housekeeping, Marie-Claire, New Woman, Red, She, Tatler, Vogue, Woman and Home and Zest. The corpus includes a smaller set of men's magazines (Men's Health, GQ and Esquire) over the same period, but I do not refer to these here. Magazines were sampled on three occasions, in Spring 2004, Summer 2004 and early 2005, and the data set comprised 40 magazines. The texts I comment on are broadly representative of many others in the data set, and the texts chosen had, at the time of sampling, high prominence. The extracts are reproduced with layout, upper/lower case and font (except for font size), bolded text and underlining generally as in the original sources. Line numbering has been added to some extracts, for ease of reference. An ellipsis indicates that text has been omitted. The following notation is used in the clips: (.) untimed short pause; (2.0) pause timed in seconds; ((all)) unclear: best guess; (presenter looks agape) informal commentary on style or context of following utterance(s); = 'latched' utterances (following each other without perceptible pause); underlining emphasis.

2 It is interesting to see how Shakespeare makes facial and bodily appearance salient to progress through the different ages, as the verse proceeds. The schoolboy, for example, has a 'shining morning face'; the soldier is 'bearded like the pard'; the justice is, 'In fair round belly, with good capon lin'd, With eyes severe, and beard of formal cut'; then 'The sixth age shifts Into the lean and slipper'd pantaloon, With spectacles on nose, and pouch on side, His youthful hose well sav'd, a world too wide, For his shrunk shank'; in the final age, the figure is 'Sans teeth, sans eyes, sans taste, sans everything'.

3 On the Lorraine television programme broadcast by the UK ITV station on 25January 2005 at $8.35 \mathrm{am}$, viewers were given make-up and grooming tips over the course of a week's programmes on 'how to look io years younger in io minutes'.

4 The following quotation from an article 'What's your summer style?' in the April 2005 issue of Marie-Claire magazine illustrates the use of the term 'down-ageing' in media texts: 'Colin McDowall, my style colleague, says that women can get away with dressing at least five years younger in summer, so enjoy your down-ageing moment' (p. I56).

5 Some make-over programmes are not ostensibly primarily focused on 'down-ageing' but make it a regular theme, by promoting 'anti-ageing' beauty products or evaluating participants' changed appearance on the basis of their looking younger. Such programmes include How to Look Good Naked, Make Me Perfect, Who Do You Think You Are? and How Do I Look? They provide an interesting ideological contrast with the examples we are considering in this paper. Turn Back Your Body Clock and Make My Body Younger are devoted to evaluating and transforming how healthy subjects are 'on the inside', with the professed aim of transforming health/lifestyle choices and extending subjects' life expectancy. The following example is from Turn Back Your Body Clock: 'Straight-talking surgeon and GP, Dr Una Coales ... each week ... meets someone whose toxic habits and lifestyle choices have seen their body go to pot. By assessing the extent of the damage with a battery of tests, she gives them a shocking wake-up call, including their estimated life expectancy' (see http:// www.channel4.com/life/microsites/T/tbybc/index.html [Accessed 30 April 2008]).

6 The text is available on the Channel 4 website at http://www.channel4.com/health/ microsites/L/lust4life/look_young/donna_f2.html [Accessed I3 June 2006]. 
7 Carnaby Street is in the West End shopping district of London, and has been associated with young people's new-fashion clothes shops since the ig6os.

\section{References}

Aapola, S. 2002. Exploring dimensions of age in young people's lives: a discourse analytical approach. Time and Society, I I , 2/3, 295-3I4.

Adam, B. 1990. Time and Social Theory. Polity, Cambridge.

Adam, B. I995. Timewatch: The Social Analysis of Time. Polity, Cambridge.

Baars, J. 2007. Chronological time and chronological age: problems of temporal diversity. In Baars, J. and Visser, H. (eds), Ageing and Time: Multidisciplinary Perspectives. Baywood, Amityville, New York, I-I3.

Barthes, R. 1973 [1957]. Mythologies. Granada/Palladin, London.

Brown, P. and Levinson, L. 1987 [1978]. Politeness: Some Universals in Language Usage. Cambridge University Press, Cambridge.

Bytheway, B. 2009. Writing about age, birthdays and the passage of time. Ageing E्E Society, 29, 6, 88I-99.

Chudacoff, H. P. ig89. How Old Are You? Age Consciousness in American Culture. Princeton University Press, Princeton, New Jersey.

Clarke, L. H. and Griffin, M. 2008. Visible and invisible ageing: beauty work as a response to ageism. Ageing \& Society, 28, 5, 653-74.

Coupland, J. 2003. Ageist ideology and discourses of control in skin care product marketing. In Coupland, J. and Gwyn, R. (eds), Discourse, the Body and Identity. Macmillan Palgrave, London, I27-50.

Coupland, J. 2007. Gendered discourses on the 'problem' of aging: consumerized solutions. Discourse and Communication, I, I, 37-62.

Coupland, J. and Coupland, N. 2009. Attributing stance in discourses of body shape and weight loss. In Jaffe, A. (ed.), Stance: Sociolinguistic Perspectives. Oxford University Press, Oxford, 227-49.

Coupland, N. 2004. Age in social and sociolinguistic theory. In Nussbaum, J. and Coupland, J. (eds), Handbook of Communication and Aging Research. Second edition, Lawrence Erlbaum, Mahwah, New Jersey, 69-9o.

Coupland, N., Coupland, J. and Giles, H. I991. Language Society and the Elderly: Discourse, Identity and Ageing. Blackwell, Oxford.

Dovey, J. 2000. Freakshow: First Person Media and Factual Television. Pluto, London.

Eagleton, T. г99. Ideology: An Introduction. Verso, London.

Featherstone, M. I99I. The body in consumer culture. In Featherstone, M., Hepworth, M. and Turner, B. (eds), The Body: Social Process and Cultural Theory. Sage, London, I7o-96.

Featherstone, M. and Hepworth, M. I99o. Images of ageing. In Bond, J. and Coleman, P. (eds), Aging in Society: An Introduction to Social Gerontology. Sage, London, 250-75.

Giddens, A. I981. A Contemporary Critique of Historical Materialism, Power, Property and the State. Macmillan, London.

Goffman, E. 1959. The Presentation of Self in Everyday Life. Doubleday, New York.

Hall, E. T. 1973. The Silent Language. Anchor Doubleday, Garden City, New York.

Harré, R. ig83. Personal Being. Blackwell, Oxford.

Hawkes, T. 1972. Metaphor. Methuen, London.

Hepworth, M. 2004. Images of ageing. In Nussbaum, J. and Coupland, J. (eds), Handbook of Communication and Aging Research. Erlbaum, Mahwah, New Jersey, 3-29.

Lakoff, G. and Turner, M. I989. More than Cool Reason: A Field Guide to Poetic Metaphor. University of Chicago Press, Chicago. 


\section{Justine Coupland}

Laslett, P. 1989. A Fresh Map of Life: The Emergence of the Third Age. Weidenfeld and Nicholson, London.

MacDonald, M. 2003. Exploring Media Discourse. Edward Arnold, London.

Murray, K. 1990. The construction of identity in the narratives of romance and comedy. In Shotter, J. and Gergen, K. J. (eds), Texts of Identity. Sage, London, I76-205.

Ornstein, R. I975. On the Experience of Time. Penguin, Harmondsworth, UK.

Shallis, M. I983. On Time. Penguin, Harmondsworth, UK.

Shilling, C. I993. The Body and Social Theory. Sage, London.

Taister, M. A., Holliday, S. D. and Borrman, H. I. M. 200o. Comments on facial aging in law enforcement investigation. Forensic Science Communications, 2, 2, I-I I. Available online at http://www.fbi.gov/hq/lab/fsc/backissu/april20oo/taister.htm [Accessed October 2008].

Tolson, A. 1996. Mediations: Text and Discourse in Media Studies. Edward Arnold, London.

Twigg, J. 2007. Clothing, age and the body: a critical review. Ageing \& Society, 27, 2, 285-305.

Vincent, J. A. 2007. Science and imagery in the 'war on old age'. Ageing E् Society, 27, $6,94 \mathrm{I}-62$.

Weigert, A. J. 1981. Sociology of Everyday Life. Longman, New York.

Woodward, K. I99I. Aging and its Discontents: Freud and Other Fictions. Indiana University Press, Bloomington, Indiana.

Address for correspondence:

Accepted 9 March 2009

Justine Coupland, Centre for Language and Communication Research, Cardiff University, Humanities Building, Colum Drive, Cardiff $\mathrm{CF}_{\mathrm{IO}}{ }_{3} \mathrm{EU}$, UK.

E-mail: CouplandJ@cf.ac.uk 